\title{
The Knowledge of Palliative Care and the Attitude Toward It Among the Nurses at Sabia General Hospital 2018
}

Manal Bilal

Omdurman Islamic University, Omdurman, Sudan

Corresponding Author:

Manal Bilal;

email:

Manalbelal52@gmail.com

Received 5 November 2018 Accepted 12 December 2018 Published 26 December 2018

Production and Hosting by Knowledge E

(a) Manal Bilal. This article is distributed under the terms of the Creative Commons Attribution License, which permits unrestricted use and redistribution provided that the original author and source are credited.

Editor-in-Chief:

Prof. Mohammad A. M. Ibnouf

\section{G OPEN ACCESS}

\section{Abstract}

Background: The aim of this study is to assess the knowledge of Palliative Care and the attitude toward it among the nurses working in Sabia General Hospitals and to find out the association between the nursing staff, knowledge, attitude, and selected demographic variables.

Material and Methods: The author performed a cross-sectional descriptive survey using a self-administered questionnaire. The total number of completed and returned questionnaires was 53, giving a 100\% response rate. The study was conducted between December 2017 and January 2018 and a simple random sampling was performed among 53 nurses working in the Sabia General Hospital.

Methodology: For data collection, a self-administrative questionnaire was developed and used for assessment by the researcher. Nurses' socio-demographic characteristics such as their age, gender, nursing qualification, department of work, work experience, training in caring terminally ill clients, and their knowledge of and attitude toward palliative care were assessed; the relation between socio demographic data and knowledge and attitude was also assessed. Results showed that respondents had fair knowledge of palliative care $27(50.9 \%)$ and fair attitude $30(56.6 \%)$. It was proved that there is a significant relation between knowledge and demographic data; $p$-value is 0.004 . Conclusion: Nurses showed poor knowledge toward palliative care and half of them showed a fair attitude.

Keywords: nurses, knowledge, attitude, palliative care

\section{Introduction}

Life-threatening diseases cause a decrease in the quality of life and they bring about various problems including physical, psychosocial, and spiritual, and especially pain. In patients with diseases that cannot be treated despite the advances in medicine, approaches aiming at reducing the patient's distress and improving the quality of life should be applied. In accordance with this view, the approach of palliative care has been developed in order to meet the needs of patients and their relatives [1]. 
Palliative care refers to the comfort care that is given to terminally ill person so as to promote comfort and relieve pain. The goal of this care is to provide comfort and highest-quality life; and to not only cure patients, but also address their mental and spiritual needs along with the physical ones [2].

The term 'palliative' is derived from the Latin word 'pallium', meaning a piece of cloth or a curtain [3].

One essential characteristics of palliative care is the necessity of the team approach. The nurse who spends a long time with patients and aims to give them the best-quality care has a prominent place in this team. This is because a nurse is the one member of the health discipline who deals with the life-threatening diseases most closely and directly provides care to patients whose death is imminent [4]

Nurses are highest in number when it comes to the healthcare providers in almost every country; they are often the primary caregivers. Nurses have been historically involved in the provision of palliative care. They have played various roles in the development of palliative care, offering leadership, support, and focus for the movement [5].

It is necessary for the palliative patients to be admitted to hospital because the problems cannot be handled at home due to the insufficient family care. More than half of the home patients move in their last months only to die because of acute medical problems, lack of professional homecare, or an overload of the informal care [6].

A very important value for palliative care is to enable people to make decision regarding the selection of their end-of-life care and the place of death. Data also suggest that most people with advanced illnesses prefer to be cared for and die at home or close to it [7].

Nurses as well as other healthcare workers often feel unprepared for their tasks in palliative care and are in much need of more expertise in the field of pain and symptom management, communication, and dealing with ethical dilemmas [8].

Aim of the study: To assess the knowledge of palliative care and attitude toward it among the nurses working in Sabia General Hospital and to find the association between the nursing staff, knowledge, attitude, and selected demographic variables.

\section{Methodology}

\subsection{Study design}

Descriptive cross-sectional study was used for conducting the study. 


\subsubsection{Study setting}

The data were collected from ICU, ER, Medical wards, and Surgical wards at Sabia General Hospital.

\subsubsection{Study period}

The study was conducted between December 2017 and January 2018.

\subsubsection{Study sample}

Simple random sampling consisted of 53 nurses working in the Sabia General Hospital.

\subsubsection{Methodology}

For data collection, a self-administrative questionnaire was developed and used for assessment by the researcher.

a. Nurses' socio-demographic characteristic such as their age, gender, nursing qualification, department of work, work experience, training in caring terminally ill clients

b. The participants' knowledge was assessed as follows: each question had true and false choices: 1 point awarded for each correct answer, o for incorrect. Correct responses were summed up to get a total knowledge score for each participant. Total score for all questions reached 19 grades. The knowledge scores were classified into poor knowledge ( $\leq 50 \%)$, fair knowledge $(65-50 \%)$, and $(\geq 65 \%)$ good knowledge.

c. The attitude was assessed using a 5-item Likert scale (ranging from strongly agree (5) to strongly disagree (1)). It had 12-item rating scale with the highest score of 5 for each option and total possible score was 60 . The attitude scores were categorized into good $(\geq 65 \%)$, fair $(65-50 \%)$, and poor $(\leq 50 \%)$.

Data were analyzed using SPSS package, version 20. The data was analyzed using descriptive (frequency and percentage) and inferential statistics based on the objectives. 


\section{Results}

The majority of respondents, $26(49.1 \%)$ were 20 to 30 years old, followed by 18 (34.0\%) who were 31-40 years old, and 9 (17.0\%) 41-50 years old. Out of the total, $27(50.9 \%)$ were female and $26(49.1 \%)$ male. The level of education of the majority of participants, that is, $25(47.2 \%)$ of them were either a diploma or less, which is near to half of respondents. Other educational qualifications recorded included $22(41.5 \%)$ Nursing Bachelor and Nursing Master6 (11.3\%).

Around 18 (34.0\%) were from Surgical Ward, 14 (26.4\%) from Medical ward, 13 (24.5\%) from ICU, and 8 (15.1\%) from the Emergency Department.

The majority of nurses, that is $32(60.4 \%)$ of them, had less than 5 years of experience and only $18(34.0 \%)$ indicated more than 5 years of nursing experience and only $3(5.7 \%)$ had between 11 and 15 years of experience.

Respondents were asked to record if they had received training toward PC, and the findings revealed that only $21(39.6 \%)$ nurses had received the training, while 32 $(60.4 \%)$ of them did not, as shown in Table (1).

Table 2, 3 show that 27(49.1\%) nurses had poor mean score knowledge, while 26 (50.9\%) had fair mean knowledge level of palliative care.

As seen in Table 4, more than half of the nurses were more likely to disagree of palliative care being given only to dying patient, $25(47.2 \%)$, as well as they also disagree if the nurse should withdraw his/her involvement with the patient 26(49.1). Also, $22(41.5 \%)$ of them disagreed with the benefits for the chronically sick person to verbalize his/her feelings.

On the attitude that the length of time required to give nursing care to a dying person would frustrate the nurse, $31(58.5 \%)$ of them disagree, while $12(22.6 \%)$ agree.

On the attitude of the family to maintain as normal an environment as possible for the dying member, 21(39.6) disagreed, while only 11(20.8\%) agreed.

The attitude that the family should be involved in the physical care of the dying person were varied from agreeing to disagreeing, 18(34.0\%) and 16(30.2\%). Most nurses disagreed on the question about difficulties to establish close relationship with the family of dying member, 31(58.5\%). Approximately, more than half of nurses, 31(58.5), agreed with the fact that nursing care for the patient's family should continue throughout the period of grief and bereavement. It is interesting to note that Nursing care should be extended to the family of the dying person (approximately $27(50.9 \%)$. About $26.0 \%$ agreed that when a patient asks, "Nurse am I dying?," they think it is 
TABLE 1: Socio demographic data.

\begin{tabular}{|c|c|c|}
\hline Variable & Frequency & $\%$ \\
\hline \multicolumn{3}{|l|}{ Age } \\
\hline 20-30 years & 26 & 49.1 \\
\hline $31-40$ years & 18 & 34 \\
\hline 41-50 years & 9 & 17 \\
\hline \multicolumn{3}{|l|}{ Gender } \\
\hline Male & 26 & 49.1 \\
\hline Female & 27 & 50.9 \\
\hline \multicolumn{3}{|l|}{ Nursing qualification } \\
\hline Diploma or less & 25 & 47.2 \\
\hline Bachelor & 22 & 41.5 \\
\hline Master & 6 & 11.3 \\
\hline \multicolumn{3}{|l|}{ Department of work } \\
\hline Medical ward & 14 & 26.4 \\
\hline Surgical Ward & 18 & 34 \\
\hline Intensive Care Unit & 13 & 24.5 \\
\hline Emergency Department & 8 & 15.1 \\
\hline \multicolumn{3}{|l|}{ Working experience } \\
\hline Less than 5 years & 32 & 60.4 \\
\hline $5-10$ years & 18 & 34 \\
\hline 11-15 years & 3 & 5.7 \\
\hline \multicolumn{3}{|l|}{ Training toward PC } \\
\hline Yes & 21 & 39.6 \\
\hline No & 32 & 60.4 \\
\hline
\end{tabular}

best to change the Subject to something cheerful. And they would be uncomfortable if upon entering the room of a terminally ill person, they found him/her crying 21 (39.6\%) While their attitudes were slightly different regarding the fear to become friends with chronically sick and dying patients. Half of them disagree to becoming friends with the patients $27(50.9 \%)$.

Table 5 reveals that there is a high statistically significant relation between Nurses' demographic data and the total mean knowledge (0.004,) and no statistical relation between the total mean of knowledge of palliative care and the hospitals and departments of work (0.201). 
TABLE 2: Knowledge of nurses about palliative care.

Statement
Palliative care should be applied as early as possible in
patients with chronic and life-threatening diseases
Palliative care is one of the most important
components of cancer prevention
Palliative care is a service that starts as soon as
diagnosis is made in patients with cancer
Palliative care is a service only for patients with cancer
Palliative care is essentially the care for terminally ill
patients
Palliative care helps patients to relieve pain and to
improve the quality of care
Palliative care is a therapeutic care
Palliative care seeks to maximize the functional
capacity of the individual by being sensitive to
religious values, beliefs, culture, and individuality
Palliative care should be started when medical and
surgical methods of treatment are ineffective
Palliative care helps patients to relieve pain and
suffering during the terminal period and provides a
good death without losing one's dignity

\begin{tabular}{|l|l|}
\hline True(\%) & False(\%) \\
\hline $41(77.4)$ & $12(22.6)$ \\
\hline $12(22.6)$ & $41(77.4)$ \\
\hline $21(39.6)$ & $32(60.4)$ \\
\hline $32(60.4)$ & $21(39.6)$ \\
\hline $32(60.4)$ & $21(39.6)$ \\
\hline $15(28.3)$ & $38(71.7)$ \\
\hline $30(56.6)$ & $23(43.4)$ \\
\hline $26(49.1)$ & $27(50.9)$ \\
\hline $21(39.6)$ & $32(60.4)$ \\
\hline $31(58.5)$ & $22(41.5)$ \\
\hline
\end{tabular}

\section{Discussion}

In this study, the respondents' age ranges between 21 and25, which represents $50 \%$ with a diploma or less, also, most of them are female; half of them did not receive any training program for palliative care, and their experience is less than 5 years.

It is necessary for nurses to have good knowledge and attitude toward palliative care, and assessing nursing knowledge and attitude is also important because knowledge and good attitude play an important role in delegating care to the dying member.

Regarding their knowledge about palliative care, their mean knowledge was between fair and poor. In this study, the description of knowledge scores have shown that $50.9 \%$ had fair knowledge and $49.1 \%$ had poor knowledge about palliative care. To the contrary, the same study was conducted in Addis Ababa, and the findings showed that $30.5 \%$ of nurses had a good knowledge about the palliative care [9]. The poor or fair knowledge in this study may be due to the lack of updating information regarding palliative care, and this might be due to the fact that PC education program was not carried out regularly in the hospital, or the nurses have to overwork in bedside care due to the shortage in the nursing staff. Due to which they have limited time to enhance and update their knowledge on palliative care. 
TABLE 3: Knowledge of nurses about palliative care.

Statement
Palliative care is applied regardless of whether the
individual receives treatment
In the palliative care approach, family members are
supported during disease process and during grief
period after the death
Palliative care only consists of pain control
Palliative care neither slows down nor accelerates
death
In palliative care the continuity of care is maintained
by being together with the patient everywhere
including hospital, home, mobile clinic, day care
center, and nursing home
Persons who benefit from palliative care should
contact with health professionals at any time
Chronic diseases such as chronic obstructive
pulmonary disease are also included in the context of
palliative care
Palliative care and hospice care serve the same
purpose
Palliative care team includes physicians, nurses, social
workers, psychologists physiotherapists, dieticians,
pharmacists, chaplains, patients' relatives, and
volunteers
Mean knowledge
Good (> 65\%)
Fair ( $50-65 \%$ )
Poor (< $50 \%$ )

\begin{tabular}{|c|c|}
\hline Yes(\%) & No(\%) \\
\hline $30(56.6)$ & $23(43.4)$ \\
\hline $31(58.5)$ & $22(41.5)$ \\
\hline $31(58.5)$ & $22(41.5)$ \\
\hline $38(71.7)$ & $15(28.3)$ \\
\hline $43(81.1)$ & 10(18.9) \\
\hline $25(47.2)$ & $28(52.8)$ \\
\hline $35(66.0)$ & $18(34)$ \\
\hline $28(52.8)$ & $25(47.2$ \\
\hline $38(71.7)$ & $15(28.3)$ \\
\hline No & $\%$ \\
\hline 0 & 0 \\
\hline 27 & 50.9 \\
\hline 26 & 49.1 \\
\hline
\end{tabular}

In similar a study conducted in the Northern districts, Palestine, the mean knowledge of participants turned out to be poor (45.8\%), which in a way supports our study [10].

The description of attitude shows that the mean scores of respondents, 30 (56.6\%) of them had fair attitude and $23(43.4 \%)$ had poor attitude toward palliative care.

This finding is in contrary with the findings of the study conducted in Addis Ababa, where 259 (76\%) had favorable attitude toward PC [9].

Additionally, another study conducted in India indicated that $92.8 \%$ of nursing students had favorable attitude $(56.7 \pm 8.5)$ toward palliative care which is in contrary to this study [11].

With respect to Correlation between knowledge, attitude, and socio demographic data (age, gender, qualification, and work experience), there is a significant relation between knowledge and socio demographic data like age, period of experience, and qualification, $p$-value 0.004 . It means when the nurses' experience and qualification 
TABLE 4: Attitude of nurses toward palliative care.

\begin{tabular}{|c|c|c|c|c|c|}
\hline Statement & $\begin{array}{l}\text { Strongly } \\
\text { disagree }\end{array}$ & Disagree & Uncertain & Agree & $\begin{array}{l}\text { Strongly } \\
\text { agree }\end{array}$ \\
\hline $\begin{array}{l}\text { Palliative care is given only to the } \\
\text { dying patient }\end{array}$ & $25(47.2)$ & $9(17.0)$ & $6(11.3)$ & 0 & $13(24.5)$ \\
\hline $\begin{array}{l}\text { As a patient nears death; the nurse } \\
\text { should withdraw from his/her } \\
\text { involvement with the patient }\end{array}$ & $26(49.1)$ & $17(32.1)$ & $1(1.9)$ & 1(1.9) & $8(15.1)$ \\
\hline $\begin{array}{l}\text { It is beneficial for the chronically } \\
\text { sick person to verbalize his/her } \\
\text { feelings }\end{array}$ & $22(41.5)$ & $4(7.5)$ & $3(5.7)$ & $5(9.4)$ & $19(35.8)$ \\
\hline $\begin{array}{l}\text { The length of time required to give } \\
\text { nursing care to a dying person } \\
\text { would frustrate me }\end{array}$ & $31(58.5)$ & $6(11.3)$ & $1(1.9)$ & $3(5.7)$ & $12(22.6)$ \\
\hline $\begin{array}{l}\text { Family should maintain as normal } \\
\text { an environment as possible for their } \\
\text { dying member }\end{array}$ & $21(39.6)$ & $17(32.1)$ & $3(5.7)$ & 1(1.9) & $11(20.8)$ \\
\hline $\begin{array}{l}\text { The family should be involved in the } \\
\text { physical care of the dying person }\end{array}$ & $16(30.2)$ & $2(3.8)$ & $2(3.8)$ & $15(28.3)$ & $18(34.0)$ \\
\hline $\begin{array}{l}\text { It is difficult to form a close } \\
\text { relationship with the family of a } \\
\text { dying member }\end{array}$ & $31(58.5)$ & $3(5.7)$ & $1(1.9)$ & $13(24.5)$ & $5(9.4)$ \\
\hline $\begin{array}{l}\text { Nursing care for the patient's family } \\
\text { should continue throughout the } \\
\text { period of grief and bereavement }\end{array}$ & $5(9.4)$ & $3(5.7)$ & $1(1.9)$ & $13(24.5)$ & $31(58.5)$ \\
\hline $\begin{array}{l}\text { Nursing care should extend to the } \\
\text { family of the dying person }\end{array}$ & 0 & $13(24 \cdot 5)$ & $1(1.9)$ & $27(50.9)$ & 22.6)) 12 \\
\hline $\begin{array}{l}\text { When a patient asks, "Nurse am I } \\
\text { dying?," I think it is best to change } \\
\text { the Subject to something cheerful }\end{array}$ & $27(50.9)$ & $13(24.5)$ & $1(1.9)$ & 0 & $12(22.6)$ \\
\hline $\begin{array}{l}\text { I am afraid to become friends with } \\
\text { chronically sick and dying patients }\end{array}$ & $27(50.9)$ & $13(24 \cdot 5)$ & 1(1.9) & 0 & $12(22.6)$ \\
\hline $\begin{array}{l}\text { I would be uncomfortable if I } \\
\text { entered the room of a terminally ill } \\
\text { person and found him/her crying }\end{array}$ & $9(17.0)$ & $5(9.4)$ & $3(5.7)$ & $15(28.3)$ & $21(39.6)$ \\
\hline Mean attitude & Frequency & & $\%$ & & \\
\hline Good $(>65 \%)$ & 0 & & 0 & & \\
\hline Fair $(50-65 \%)$ & 30 & & 56.6 & & \\
\hline Poor $(<50 \%)$ & 23 & & 43.4 & & \\
\hline
\end{tabular}

increase, their favorable knowledge also improves, which is similar to the study conducted in India, where they found a significant relation between knowledge and demographic data(age), $p$-value 0.01 [1], while the correlation between attitude and demographic data is insignificant $p$-value 0.201 . 
TABLE 5: Association between mean scores of knowledge of and attitude toward the palliative care with selected variables.

\begin{tabular}{|l|c|c|c|}
\hline Item & Mean & SD & P-value \\
\hline Knowledge & & & \\
\hline Age & 1.6792 & 0.7538 & \\
\hline Gender & 1.5094 & 0.50469 & \\
\hline Nursing qualification & 1.6981 & 0.74897 & \\
\hline Work experience & 1.4528 & 0.60657 & 0.004 \\
\hline Attitudes & & & \\
\hline Age & 1.6792 & 0.7538 & 0.201 \\
\hline Gender & 1.5094 & 0.50469 & \\
\hline Nursing qualification & 1.6981 & 0.74897 & \\
\hline Work experience & 1.4528 & 0.60657 & \\
\hline
\end{tabular}

\section{Conclusions and Recommendations}

At the end of this study, it was found that nursing students' knowledge about the concepts of palliative care was poor and attitude was fair; it was affected by sociodemographic characteristics such as age, gender, and qualification, and work experience significantly more than the knowledge.

\section{References}

[1] Elçigil, A. (2012). Palliative care nursing. Gülhane Tıp Derg, vol. 54, pp. 329-334.

[2] Retrieved from http://www.growthhouse.org/palliat.html [cited in 2010].

[3] Pastrana, T., Jünger, S., Ostgathe, C., et al. (2008). A matter of definition key elements identified in a discourse analysis of definitions of palliative care. Palliative Medicine, vol. 22, no. 3, pp. 222-232.

[4] Prem, V., Karvannan, H., Kumar, S. P., et al. (2012). Study of nurses' knowledge about palliative care: A quantitative cross-sectional survey. Indian Journal of Palliative Care, vol. 18, no. 2, pp. 122-127.

[5] Allen, D. and Marshall, E. S. (2008). Children with HIV/AIDS: A vulnerable population with unique needs for palliative care. Journal of Hospice \& Palliative Nursing „Pp. 10359-10367.

[6] Visser, G. (2006). Mantelzorg in de palliatief terminale fase. Den Haag: NIZW Zorg/Lemma.

[7] Tang, S. T. (2003). When death is imminent: Where terminally ill patients with cancer prefer to die and why. Concer Nursing, vol. 26, pp. 245-251. 
[8] Armes, P. J. and Addington-Hall, J. M. (2003). Perspectives on symptom control in patients receiving community palliative care. Palliative Medicine, vol. 17, no. 7, pp. 608-615.

[9] Kassa, H., Murugan, R., Zewdu, F., et al. (2014). Assessment of knowledge, attitude and practice and associated factors towards palliative care among nurses working in selected hospitals, Addis Ababa, Ethiopia. BMC Palliative Care, vol. 13, no. 6.

[10] Ayed, A., Sayej, S., Harazneh, L., et al. (2015). The nurses' knowledge and attitudes towards the palliative care. Journal of Education and Practice, vol. 6, no. 4, pp. 91-99.

[11] Karkada, S., Nayak, B., and Malathi. (2011). Awareness of palliative care among diploma nursing students. Indian Journal of Palliative Care, vol. 17, no. 1, pp. 20-23. 